\title{
Study on Module Selection Method for Customized Products
}

\author{
Hang Liu* \\ School of Management Science and Engineering, Zhengzhou Institute of Aeronautical Industry Management, \\ Zhengzhou, China \\ Email: liuhang@zzia.edu.cn
}

Received 14 September 2014; revised 6 October 2014; accepted 16 October 2014

Copyright (C) 2014 by author and Scientific Research Publishing Inc.

This work is licensed under the Creative Commons Attribution International License (CC BY). http://creativecommons.org/licenses/by/4.0/

(c) (i) Open Access

\begin{abstract}
Modularization is the key technique for modern manufacturing system, which resolves the conflict between flexibility and productivity. The challenge of deciding which modules should choose under resource limitation from a large amount of available alternative modules has been well recognized in academia and industry correspondingly in producing customized production. For this reason, this paper proposes a new module selection method to deal with the problem, which combines rough set theory into total quality development (QFD) framework. First of all, a decision table is build up and then be modified through examining the importance of each attribute. Afterwards, the basic importance rating vector is calculated and the modifying index of the importance will be determined to get the final result. Finally, the feasibility and efficiency of the proposed method is manifested by a case study.
\end{abstract}

\section{Keywords}

Module Selection, Rough Set Theory, QFD, Resource Limitation

\section{Introduction}

With the intensive competition among manufacturing industry, manufacturers must have the abilities to differentiate their products according to individual customer needs as well as to keep and even better to improve the efficiency, effectiveness, and the low cost that customers expect. Customized services are an important source of revenue for many companies, particularly those whose customer satisfaction is of supreme importance. This marketing approach has resulted in the attempting of increasingly diverse products in order to satisfy most segments of the market [1]. Whether a company can provide customized products depends on the flexibility of their production systems which are based on a common platform, with a set of options which makes it possible to ${ }^{*}$ This paper is supported by National Natural Science Foundation, China (No. 51475290, 51075261), Henan Science and Technology Department Soft Science Project (No. 122400450223). 
achieve the desired diversity.

The challenge of building customized production rapidly while at the same time maintaining the same profit as mass production has been well recognized in academia and industry correspondingly [2]. The product often cannot be produced in a customer-required short time or at a customer-determined price [3]. Several scholars proposed that the strategy of manufacturing modules in advance makes it possible to solve this difficulty.

Modularization is a high effective method to provide customized products or services based on economical and flexible development by allowing highly differentiated products to be developed from a common platform while targeting individual products to distinct market segments. With the modular design approach, new products can be quickly developed by using alternative modules. The relevant combinations of modules can form different final products which meet customers' various demands. As common modules can be shared by different products, the time and cost of design and manufacturing can then be reduced significantly. In modular design and manufacture process, all possible functional modules will be first selected from the module base to meet specific customer requirements. Product modularization faces many challenges and the resource shortage is the most common difficulty that happens in almost every enterprises. The manufacturing enterprises usually cannot have enough resources to implement all functional modules that have been selected in the first step into the real manufacturing process. Thus, the manufacturers have to decide which of those modules should be kept for the next step under certain limitation in a short response time due to the rapid introduction of new products.

The objective in this article is to develop an acceptable resource-constrained module selection method for meeting maximum customer satisfaction by using Rough-QFD theory. This proposed model combines rough set theory into total quality development (QFD) framework. In this method, decision tables are built up and modified through examining the importance of each attribute. Afterwards, the basic importance rating vector is calculated and the modifying index of the importance will be determined to get the final result. The remainder of this article is organized as follows. Section 2 reviews related literature and background information on modular design as well as QFD and Rough set theory applications. Section 3 describes customized product innovation process. Section 4 presents the module selection method based on the combination of QFD and Rough set theory. Section 5 conduct a case study by using the method proposed in Section 4. Closing remarks are presented in Section 6.

\section{Literature Review}

\subsection{Modular Design}

Several strategies about modular design and module selection were proposed in the literature by many literates. Fujita [4] determines the contents of modules and their combinations under an optimization view. He pointed out that it is necessary to develop a quantitative and systematic approach to examine all possible combinations of the available alternative modules. Gonzalez and Otto [5] developed a general optimization formulation for a product family design based on a traditional decision model. Yigit et al. [6] introduced a nonlinear integer programming model to select subsets of module instances in reconfigurable manufacturing systems. Swaminathan and Tayur [7] discuss the optimal configuration of inventory levels of modules that can serve more than one final product. In general, these previous literature mainly focus on the optimization of module combinations. Limited research in module selection direction is viewed from the product itself or the manufacturing system. The resource limitation and the voice of customer have not been taken into account. However, those two elements are extremely important in the customization environment of current manufacturing industry. Therefore, this paper will study on resource limited module selection method under the optimization of customer satisfaction.

\subsection{Quality Function Deployment (QFD) and Rough Set Theory}

Quality function deployment (QFD), developed by Dr. Yoji Akao in Japan in 1966, is a strategic management technique typically used for identifying and translating customer wants into technical specifications for product (or service) planning, design, processes, and production [8]. Furthermore, it is a technique exclusively used to determine the prioritization of customer satisfaction. In a word, QFD is a customer-oriented product development technique that links customer expectations to the technical characteristics of the product [9] [10]. The general format of QFD is a matrix made up of six major components (Figure 1).

In application of traditional QFD method, the accuracy of prioritization result is influenced by how specified the evaluation criterions are. However, Different from the material resources, the customer satisfaction is ab- 


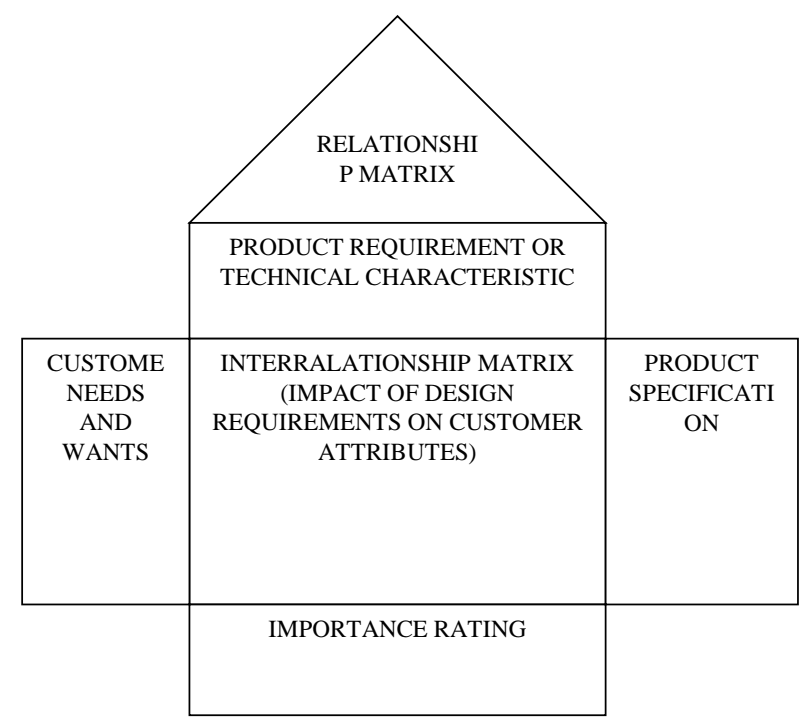

Figure 1. A basic QFD matrix.

stract, dynamic and complex. The information is usually incomplete because it is quite impossible for the end users to express their entire wants clearly in technical terms. Hence, Rough set theory is considered to be integrated within a QFD framework to cope with this weakness. Rough set theory is an effective widely recognized mathematical tool for processing incomplete and uncertainty problems, proposed by Pawla in 1982 [8]. The theory is to determine classification under certain conditions through the data simplification. Using rough sets theory, decision can be directly made based on an incomplete information system. Besides, it does not require additional information and a priori knowledge, which means that it has high practicability and easy to be implemented.

Rough set theory was proposed by Pawlak (1981). It is a new mathematical tool to deal with inconsistent, ambiguity, and incomplete information. Rough sets can be used to represent, vagueness and general uncertainty. Rough set theory is useful for rule induction from those incomplete data sets.

This paper proposes a systematic module selection method by combining Rough Set theory with QFD method. There are four hypotheses that will be used in this paper and be illustrated below [11] [12].

Hypothesis 1: $A=(U, N, V, f)$ is an expression system. Where $U$ represents an object of a non-empty finite sets, called Domains; $N$ represents a non-empty finite set of attributes, $N=T \cup J, T \cap J=\varnothing, T$ is called a condition attribute set, $J$ is called a decision attribute set; $V=U_{n \in N} V_{n}, V_{n}$ is the range of $n$; $f$ :

$U \times N \rightarrow V$ is an information function, which gives a message value for each attribute, that $\forall n \in N \quad u \in U$,. $f(u, n) \in \forall n$

Hypothesis 2: There is an equivalence relation $R, r \in R$. If the $\operatorname{IND}(R)=\operatorname{IND}(R-\{r\})$, then $r$ could be removed from $R$.

Hhypothesis 3: There is an equivalence relation in $U: P$ and $Q$. The positive area $P$ is the object set which contains all classification information of $U / P$ that can be accurately classified into $Q$, symbolized as $\operatorname{Pos} P(Q)$.

$$
\operatorname{Pos} P(Q)=\sum_{U_{e} U} P(U)
$$

Hypothesis 4: set up a decision table $B, B=(U, N, T, J)$. If $\alpha$ is the dependency degree of $J$ on $T$ $(0 \leq \alpha \leq 1)$, then

$$
\alpha=\frac{\sum \operatorname{Pos} T(J)}{\sum J(U)}
$$

$\operatorname{Pos} T(J)$ means that $T$ is the positive area of $J$. Besides, $\beta(n)$ is called the importance of attribute $n$.

$$
\beta(n)=\alpha(T, J)-\gamma(T-\{n\}, J)
$$




\section{Analysis of Customized Product Innovation Process}

Within a customization environment in modern manufacturing industry, customer satisfaction is becoming supreme important. The nuclear purpose of launching new product is to achieve the maximum customer happiness. Therefore, the module selection process should have special consideration of customer satisfaction. The enterprises should take all possible functional modules into the comprehensive consideration, analyze the priority and decide which of them need to be launched into final product to achieve maximum customer satisfaction.

The design specification of customized products are transformed and ultimately determined by end user requirements. The customer's requirements guide the direction of the innovation of customized products. Meanwhile, customized product innovation can then improve the demand level of customers. Therefore, the innovation process and the customer requirements form a good dynamic circulation of each other. Form the point of transformation mechanism, the innovation chain trends waveform forward (as shown in Figure 2). When the customize product temporarily meets the customer requirements, with the enhancement of customers' cognitive degree on the system function and the change of internal and external environment, the end customers will produce new implicit requirements. This would cause the manufactures conduct a second round of product innovation. Concisely, the whole innovation chain interweaves waveform forward.

The whole conversion and the innovation process can be divided into the following four steps: identification and predictions of customer requirements; development selection of customer requirements; transformation of requirements to the product specification and the design; manufacture and production of final products. Among them, selecting the appropriate demand resources from the identified set of requirements is the crucial step of successful customized product innovation. Differed from material resources, the demand resources is abstract, dynamic and complex. It is no practical significance that converts all customer demands onto product functions under resource constraints. The risk of requirement selection is usually presented in two aspects: inaccurate demand choosing and developed more than expected. The developed new product based on inaccurate choices cannot achieve customer satisfaction. In addition, in all identified requirements, some invisible requirements of the product attributes are likely to show its actual application value after a long period of time. Therefore, if the requirements are developed excessively of inappropriately, the innovation process will increase the difficulty and the cost, extend the development cycle, and at the same time be criticized by the end customers due to providing excessive additional functionality that is no practical value. Therefore, we need to find a way to comprehensive consideration to a variety of demand, analyze the important degree of customer requirements, translate them into new products and finally achieve maximum customer satisfaction.

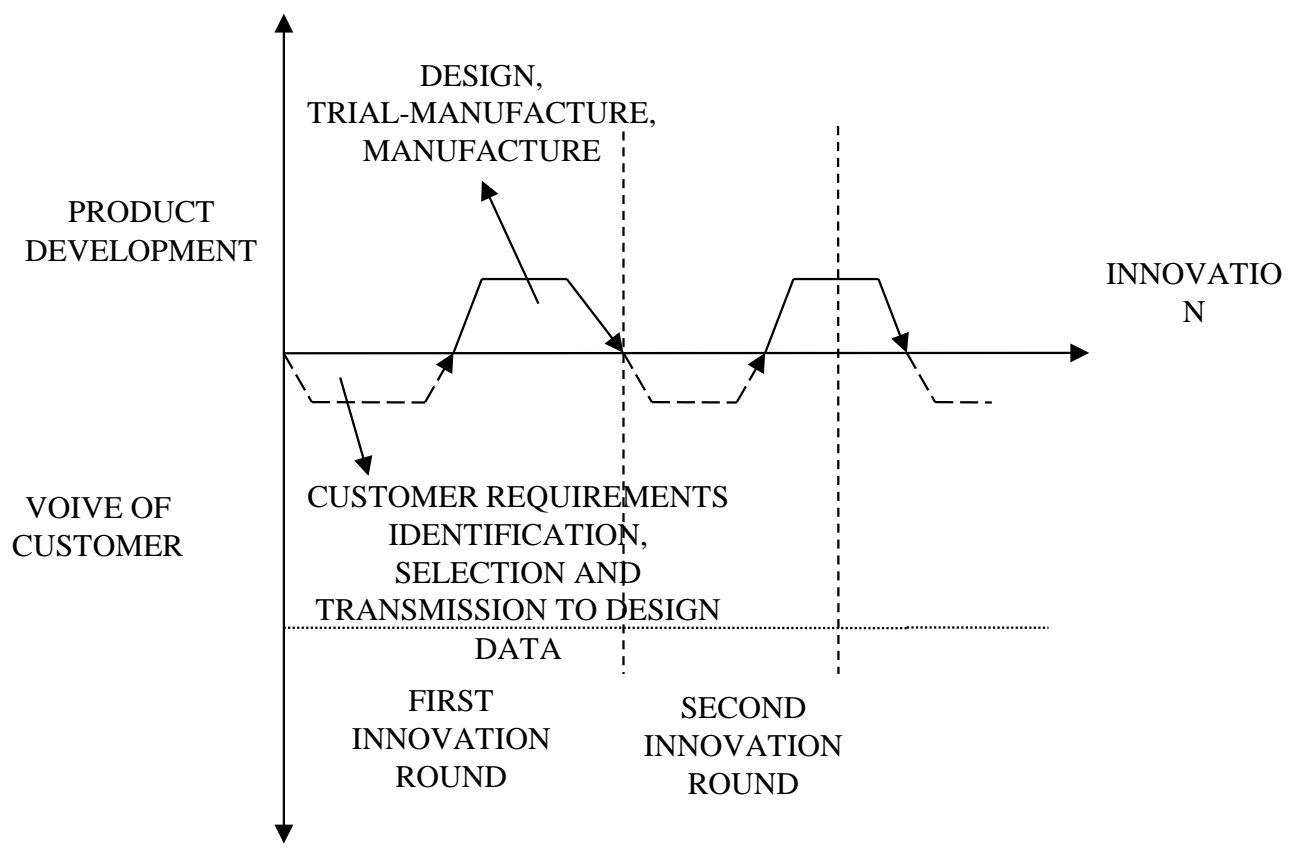

Figure 2. The process of customized product innovation. 


\section{Module Selection Method Based on Rough-QFD Theory}

Based on above analysis, the module selection process can be described as Figure 2 and determined according to the following steps:

Stept 1. Build up a decision system and transform the initial data of customer satisfaction into a decision table.

Derived from customer investigation, the fuzzy customer needs are obtained. In accordance with the acquired result, the modules $\left(M_{1}, M_{2}, \cdots, M_{i}, \cdots, M_{n}\right)$ can be select primarily to accomplish all possible customer demands. Afterwards, a second end user investigation will be implemented to get the initial data of customer satisfaction of all modules. The decision table is consisted by the modules and the data of customer satisfaction. This initial data is defined as $S L$. $T_{N}$ is a condition attributes set, $T_{N}=\left\{M_{1}, M_{2}, \cdots, M_{n}\right\} ; J_{S}$ is a decision attribute set, $J_{S}=\left\{S L_{1}, S L_{2}, \cdots, S L_{n}\right\}$. The range of each attribute depends on the practical situation. Thus, a decision system $J_{T}, \quad J_{T}=\left(U, T_{N} \cup\left\{J_{S}\right\}\right)$ can be set up.

Step 2: Examine the importance of each attribute and modify the decision table.

The original classification of the decision table built in Step 1 is utilized as a benchmark to examine how the decision table will change after deleting each attribute. If the final decision does not alter after removing an attribute, this attribute is less important and can be ignored. Otherwise, this attribute is enough important and need to be ranked in accordance with the importance in next step. The decision table should be modified and delete the relevant attributes of no use.

Step 3: Calculate the basic importance rating vector $g=\left(g_{1}, g_{2}, \cdots, g_{n}\right)$.

The importance of every condition attribute can be correspondingly used to measure the importance of functional modules in QFD. According to the importance of the condition attributes $\beta, \beta_{i}=\beta\left(M_{i}\right.$, SL $\left.L_{i}\right)$, the basic importance rating vector of the corresponding module $g=\left(g_{1}, g_{2}, \cdots, g_{n}\right)$ can be determined by using Equation (4) below (Note: in following equations, $i=1, \cdots, n$ ).

$$
g_{i}=\frac{\beta_{i}}{\sum_{i=1}^{n} \beta_{i}}
$$

Step 4: Determine the modifying index of the importance to get the final result.

The importance obtained from Step 3 is directly accessed by the end user without consideration of other factors that may affect the customer satisfaction. Therefore, the results need to be adjusted. The modifying index is defined as $\gamma, \gamma=\left(\gamma_{1}, \gamma_{2}, \cdots, \gamma_{n}\right) \gamma_{i}$. If there are $n$ impact factors: $O, P, Q, \cdots, W$, then $\gamma$ could be calculated by using flowing equation.

$$
\gamma_{i}=\left(o_{i} \times p_{i} \times q_{i} \times \cdots \times w_{i}\right) / \sum_{i=1}^{n}\left(o_{i} \times p_{i} \times q_{i} \times \cdots \times w_{i}\right)
$$

Hence, the final importance, shown as $Z_{i}$, can then be calculated and normalized by Equation (6)

$$
Z_{i}=\left(g_{i} \times \gamma_{i}\right) / \sum_{i=1}^{n}\left(g_{i} \times \gamma_{i}\right)
$$

In order to make this method more limpid, above steps are collectively shown in Figure 3.

\section{Application}

A manufacturing enterprise is planning to launch an improvement of a current complex product according to the customer's requirements. In accordance with the customer needs, four functional modules $M_{1}, M_{2}, M_{3}$ and $M_{4}$ should be added and adjusted to achieve all requirements. With the resource limitation, the enterprise can only apply two modules into the actual production. Under this circumstance, the manufacturer has to choose the most proper ones from those four modules to get the achievable maximum customer satisfaction. A second study on customer satisfaction of each module is conducted through considering the possible functions that each module could achieve in final product and the relative data are collected. There are three levels of customer satisfaction (low, medium and high), corresponding the value of 1, 2, and 3. After eliminating duplicate and redundant data, a decision table is composed by the module and the satisfaction levels and, shown as Table 1 . In Table 1 , 


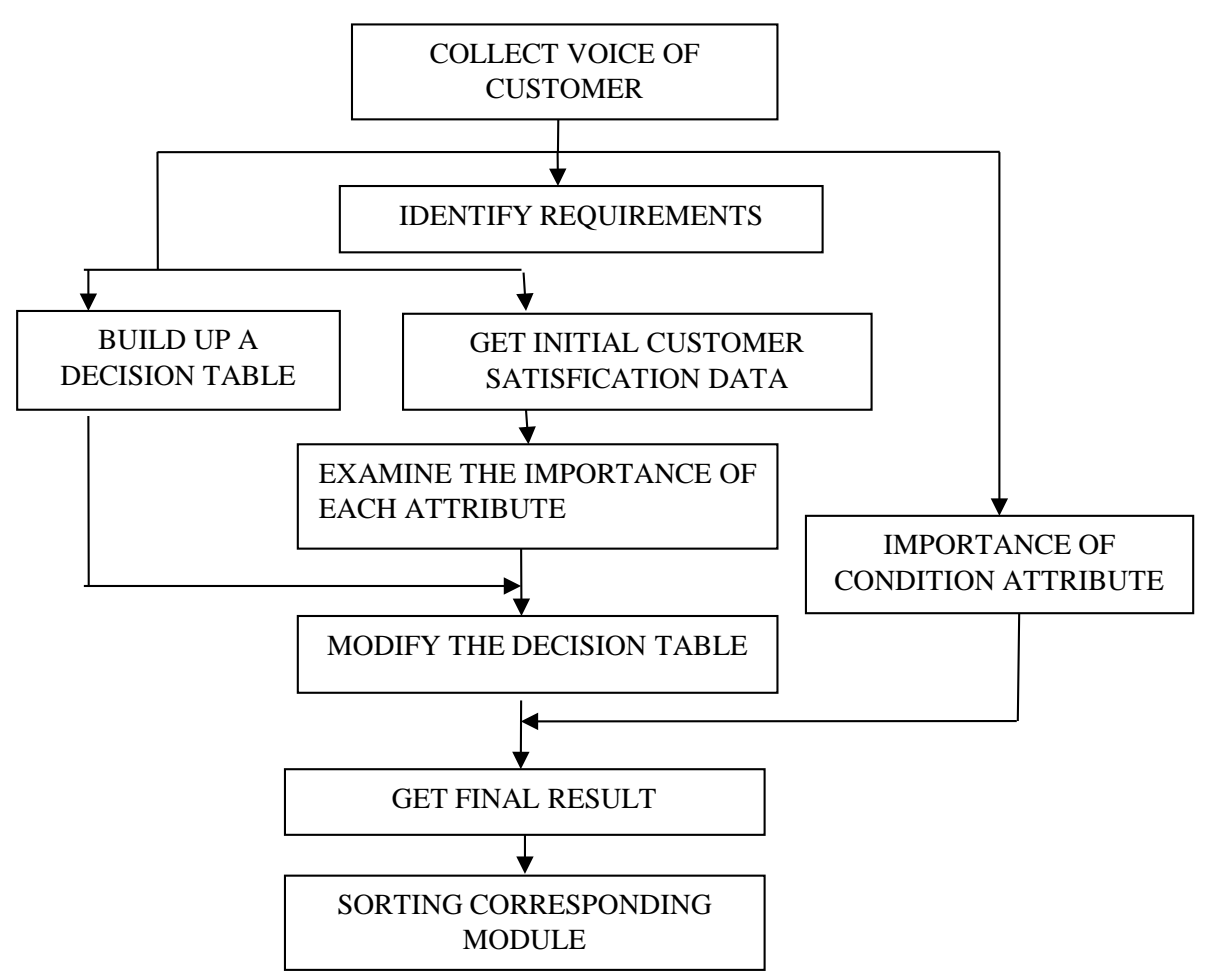

Figure 3. General framework of the method.

Table 1. The decision table.

\begin{tabular}{cccccccccccccccccc}
\hline$U$ & $T_{1}$ & $T_{2}$ & $T_{3}$ & $T_{4}$ & $J$ & $U$ & $T_{1}$ & $T_{2}$ & $T_{3}$ & $T_{4}$ & $J$ & $U$ & $T_{1}$ & $T_{2}$ & $T_{3}$ & $T_{4}$ & $J$ \\
\hline 1 & 1 & 1 & 1 & 1 & 1 & 14 & 1 & 2 & 2 & 2 & 2 & 27 & 2 & 1 & 3 & 3 & 3 \\
2 & 1 & 1 & 1 & 2 & 1 & 15 & 1 & 2 & 2 & 3 & 3 & 28 & 2 & 2 & 1 & 1 & 1 \\
3 & 1 & 1 & 1 & 3 & 2 & 16 & 1 & 2 & 3 & 1 & 3 & 29 & 2 & 2 & 1 & 2 & 2 \\
4 & 1 & 1 & 2 & 1 & 1 & 17 & 1 & 2 & 3 & 2 & 3 & 30 & 2 & 2 & 1 & 3 & 3 \\
5 & 1 & 1 & 2 & 2 & 2 & 18 & 1 & 2 & 3 & 3 & 3 & 31 & 2 & 2 & 2 & 1 & 1 \\
6 & 1 & 1 & 2 & 3 & 3 & 19 & 2 & 1 & 1 & 1 & 1 & 32 & 2 & 2 & 2 & 2 & 2 \\
7 & 1 & 1 & 3 & 1 & 2 & 20 & 2 & 1 & 1 & 2 & 2 & 33 & 2 & 2 & 2 & 3 & 3 \\
8 & 1 & 1 & 3 & 2 & 3 & 21 & 2 & 1 & 1 & 3 & 3 & 34 & 2 & 2 & 3 & 1 & 3 \\
9 & 1 & 1 & 3 & 3 & 3 & 22 & 2 & 1 & 2 & 1 & 1 & 35 & 2 & 2 & 3 & 2 & 3 \\
10 & 1 & 2 & 1 & 1 & 1 & 23 & 2 & 1 & 2 & 2 & 3 & 36 & 2 & 2 & 3 & 3 & 3 \\
11 & 1 & 2 & 1 & 2 & 1 & 24 & 2 & 1 & 2 & 3 & 3 & 37 & 2 & 2 & 2 & 2 & 3 \\
12 & 1 & 2 & 1 & 3 & 3 & 25 & 2 & 1 & 3 & 1 & 3 & & & & & & \\
13 & 1 & 2 & 2 & 1 & 2 & 26 & 2 & 1 & 3 & 2 & 3 & & & & & \\
\hline
\end{tabular}

condition attributes $T_{1}, T_{2}, T_{3}$ and $T_{4}$ respectively represent functional modules $M_{1}, M_{2}, M_{3}$ and $M_{4}$. Decision attribute $J$ represents the customer satisfaction $S L$.

According to Equation (1) and Hypothesis 2, all conditional attributes $T_{1}, T_{2}, T_{3}$ and $T_{4}$ cannot be ignored to the decision attributes $J$. Therefore, no modification is needed and the decision table will stay the same. The 
importance of all four modules needs to be positioned.

By using the Equation (2) and the data of Table 1, the dependency of condition attributes $T_{1}$ on decision attribute $J$ can be calculated below:

$$
\alpha(T, J)=\operatorname{SUM}(\operatorname{PosT}(J)) / \operatorname{SUMJ}(M)=\left(\sum V_{J m}-\left(V_{J 32}+V_{J 37}\right)\right) / \sum V_{J m}=0.946,
$$

( $V_{J m}$ refers to the value of decision attribute $J$ )

Similarly,

$$
\alpha\left(T-\left\{T_{1}\right\}, J\right)=0.595
$$

Equation (3) is used to calculate the importance:

$$
\beta\left(t_{1}\right)=\alpha(T, J)-\alpha\left(T-\left\{T_{1}\right\}, J\right)=0.351
$$

Repeating above steps, the dependency and importance of other attributes can be calculated and the results are shown in Table 2 below.

According to Equation (4), the basic importance rating vector of the modules can be calculated.

$$
g=(0.176,0.122,0.351,0.351)
$$

Through market investigation and experts' evaluation, other related information that could affect customer satisfaction of the four modules can be obtained. In this case, they are embodied in four fields: the current competitive situation (CC), the objective of the competitiveness (OC), the possibility of improvement (PI), and the market competitive advantages (CA). The results are shown in Table 3.

Equation (5) is used to calculate the modifying index based on above data.

$$
\gamma=\left(\gamma_{1}, \gamma_{2}, \gamma_{3}, \gamma_{4}\right)=(0.203,0.269,0.380,0.148) \text {. }
$$

Finally, according to Equation (6), the final importance ratings of modules in developing the complex product can be calculated.

$$
Z=\left(z_{1}, z_{2}, z_{3}, z_{4}\right)=(0.138,0.114,0.448,0.300) .
$$

The maximum value is that of $Z_{3}$, which means $M_{3}$ is the most important module and should have the highest priority. Similarly, the other modules should be chosen as the sequence of $z_{4}, z_{1}$ and $z_{2}$.

Known from above analysis, the enterprise can make decision on which model to choose under resource limitation by following the final importance sequence. In this case, the enterprise can make the final decision on applying $M_{3}$ and $M_{4}$ into the actual production.

Table 2. The result of dependency and customer satisfaction of each module.

\begin{tabular}{rcccc}
\hline & $T_{1}$ & $T_{2}$ & $T_{3}$ & $T_{4}$ \\
\hline Dependency & 0.595 & 0.703 & 0.243 & 0.243 \\
Importance & 0.351 & 0.243 & 0.703 & 0.703 \\
\hline
\end{tabular}

Table 3. Other related data.

\begin{tabular}{ccccc}
\hline & CC & OC & PI & CA \\
\hline$M_{1}$ & 4 & 2 & 0.80 & 1.2 \\
$M_{2}$ & 3 & 1 & 0.85 & 1.5 \\
$M_{3}$ & 5 & 1 & 0.75 & 1.2 \\
$M_{4}$ & 4 & 2 & 0.70 & 1.0 \\
\hline
\end{tabular}




\section{Conclusions}

The module selection is the first and crucial step for using modular technology. The approach presented in this paper provides a new methodology for solving module selection problem under resource limitation. The proposed method has a wide range of application, which takes customer satisfaction into account and avoids the risk of subjective judgments. The direct and clear result can be comprehended by the decision maker easily, which greatly improves the practicability of this method. However, whether this method provides a completely satisfactory program for decision-makers will mainly depend on whether the satisfaction obtained reflects the objective function actual level of satisfaction. There is no single unified approach, which can be employed to obtain the value of satisfaction. The specific solutions need to be carried out for specific problems. In a word, this Rough-QFD module selection method is a simple, effective and practical decision-making technique, which sets up a communication bridge between customers and manufacturers.

As time and resource limitation, this approach this paper proposed hasn't completed. There are several aspects can be further studied in the future, such as, the study of the transformation process of the customers' requirements to relative technological features.

\section{References}

[1] Tseng, M.M. and Jiao, J. (2001) Mass Customization, Handbook of Industrial Engineering. 3rd Edition, Wiley, New York.

[2] Jarratt, T.A.W., et al. (2011) Engineering Change: An Overview and Perspective on the Literature. Research in Engineering Design, 22, 103-124.

[3] Rekiek, B., Dolgui, A., Delchambre, A. and Bratcu, A. (2002) State of Art of Optimization Methods for Assembly Line Design. Annual Reviews in Control, 26, 163-174. http://dx.doi.org/10.1016/S1367-5788(02)00027-5

[4] Fujita, K. (2002) Product Variety Optimization under Modular Architecture. Computer-Aided Design, 34, 953-965. http://dx.doi.org/10.1016/S0010-4485(01)00149-X

[5] Gonzalez, J.P. and Otto, K.N. (2000) Modular Platform-Based Product Family Design. Proceedings of the DETC’00 ASME Design Engineering Technical Conferences and Computers and Information in Engineering Conference, Baltimore, 677-686.

[6] Yigit, A.S. and Allahverdi, A. (2003) Optimal Selection of Module Instance for Modular Products in Reconfigurable Manufacturing System. International Journal of Production Research, 41, 4063-4074. http://dx.doi.org/10.1080/0020754031000149220

[7] Swaminathan, K.M. and Tayur, S.R. (1998) Managing Broader Product Line through Delayed Differentiation Using Vanilla Boxes. Management Science, 44, 161-172. http://dx.doi.org/10.1287/mnsc.44.12.S161

[8] Pawlak, Z. (1991) Rough Classication. International Journal of Human-Compute Studies, 5, 369-383.

[9] Pawlak, Z. (1995) Vagueness and Uncertainty—A Rough Set Perspective. Computational Intelligence, 11, $227-232$. http://dx.doi.org/10.1111/j.1467-8640.1995.tb00029.x

[10] Almannai, B., Greenough, R. and Kay, J. (2008) A Decision Support Tool Based on QFD and FMEA or the Selection of Manufacturing Automation Technologies. Robotics and Computer Integrated Manufacturing, 24, 501-507. http://dx.doi.org/10.1016/j.rcim.2007.07.002

[11] Bottani, E. (2009) A Fuzzy QFD Approach to Achieve Agility. International Journal of Production Economics, 119, 380-391. http://dx.doi.org/10.1016/j.ijpe.2009.02.013

[12] Shah, R. and Ward, T. (2007) Defining and Developing Measures of Lean Production. Journal of Operations Management, 25, 785-805. 
Scientific Research Publishing (SCIRP) is one of the largest Open Access journal publishers. It is currently publishing more than 200 open access, online, peer-reviewed journals covering a wide range of academic disciplines. SCIRP serves the worldwide academic communities and contributes to the progress and application of science with its publication.

Other selected journals from SCIRP are listed as below. Submit your manuscript to us via either submit@scirp.org or Online Submission Portal.
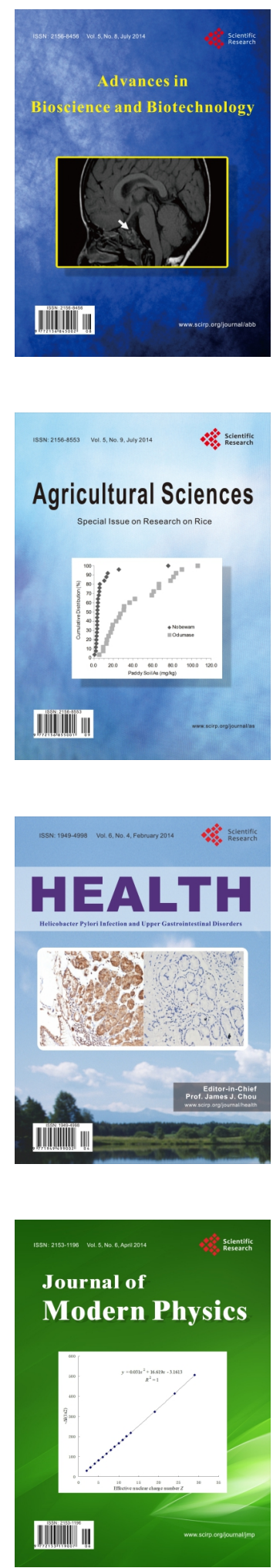
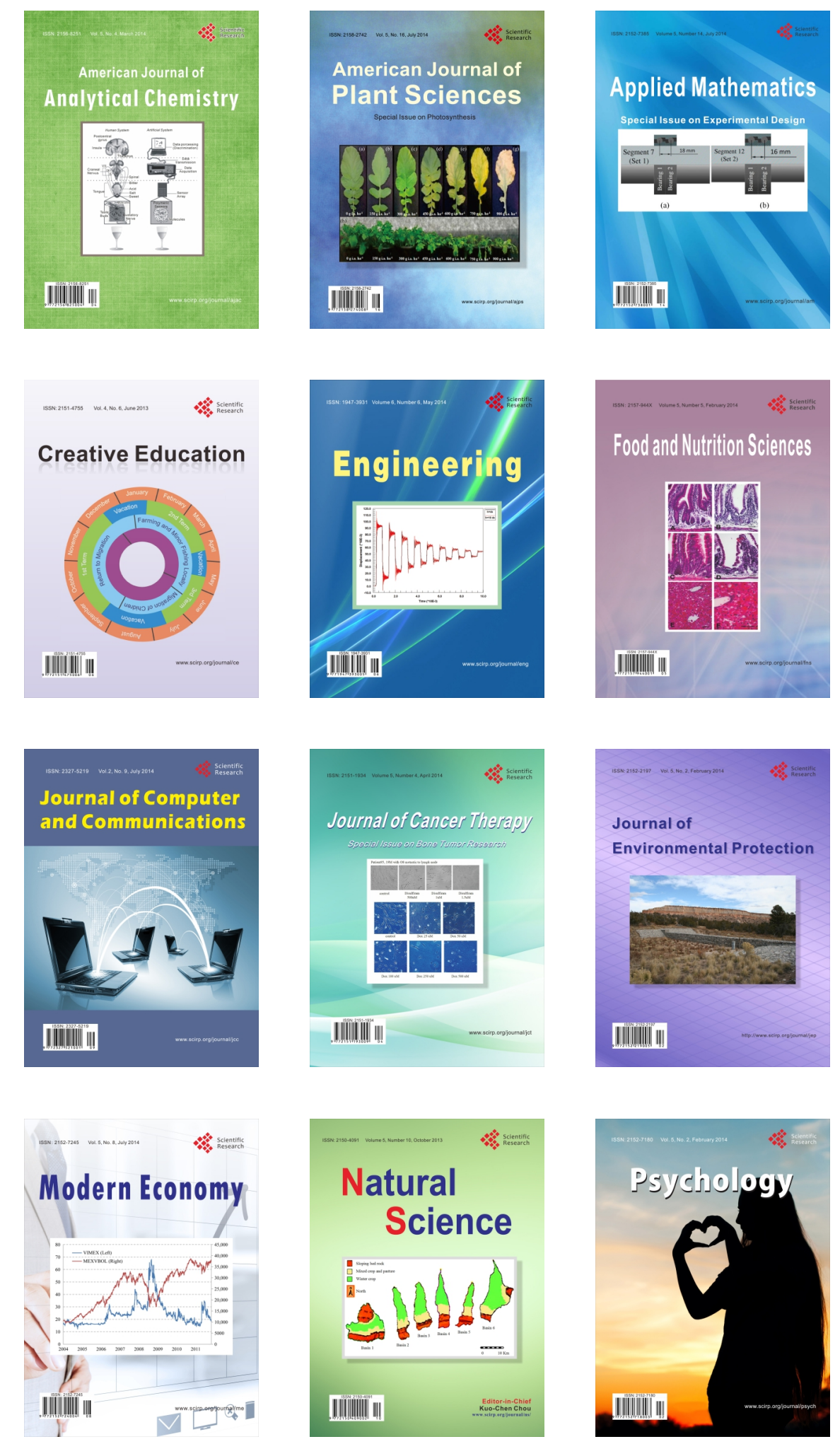